\title{
Risk Factors for Early Brain AVM Rupture: Cohort Study of Pediatric and Adult Patients
}

(D) G. Garzelli, (DE. Shotar, (D)T. Blauwblomme, (D). Sourour, (D). Alias, (D). Stricker, (D) B. Mathon, (D) M. Kossorotoff, (D) F. Gariel, (D) N. Boddaert, (D) F. Brunelle, (D)P. Meyer, DO. Naggara, (D) Clarençon, and D G. Boulouis

\begin{abstract}
BACKGROUND AND PURPOSE: Whether architectural characteristics of ruptured brain AVMs vary across the life span is unknown. We aimed to identify angioarchitectural features associated with brain AVMs ruptured early in life.

MATERIALS AND METHODS: Patients with ruptured brain AVMs referred to 2 distinct academic centers between 2000 and 2018 were pooled and retrospectively analyzed. Imaging was retrospectively reviewed for angioarchitectural characteristics, including nidus size, location, Spetzler-Martin grade, venous drainage, and arterial or nidal aneurysm. Angioarchitecture variations across age groups were analyzed using uni- and multivariable models; then cohorts were pooled and analyzed using Kaplan-Meier and Cox models to determine factors associated with earlier rupture.

RESULTS: Among 320 included patients, 122 children (mean age, $9.8 \pm 3.8$ years) and 198 adults (mean age, $43.3 \pm 15.7$ years) were analyzed. Pediatric brain AVMs were more frequently deeply located $(56.3 \%$ versus $21.2 \%, P<.001)$, with a larger nidus ( 24.2 versus $18.9 \mathrm{~mm}, P=.002)$, were less frequently nidal (15.9\% versus $23.5 \%, P=.03)$ and arterial aneurysms $(2.7 \%$ versus $17.9 \%, P<.001)$, and had similar drainage patterns or Spetzler-Martin grades. In the fully adjusted Cox model, supratentorial, deep brain AVM locations (adjusted relative risk, 1.19; 95\% Cl, 1.01-1.41; $P=.03$ and adjusted relative risk, 1.43; 95\% Cl, 1.22-1.67; $P<.001$, respectively) and exclusively deep venous drainage (adjusted relative risk, 1.46, 95\% Cl, 1.21-1.76; $P<.001$ ) were associated with earlier rupture, whereas arterial or nidal aneurysms were associated with rupture later in life.
\end{abstract}

CONCLUSIONS: The angioarchitecture of ruptured brain AVMs significantly varies across the life span. These distinct features may help to guide treatment decisions for patients with unruptured AVMs.

ABBREVIATION: $H R=$ hazard ratio

he most devastating complication of brain AVMs is their rupture, leading to intracranial hemorrhage, ${ }^{1}$ responsible for

Received June 19, 2020; accepted after revision August 6.

From the Department of Neuroradiology (L.G., O.N., G.B.), Sainte-Anne University Hospital, Institut National de la Santé et de la Recherche Médicale Unité Mixte de Recherche 1266, Paris, France; Departments of Neuroradiology (L.G., F.C.) and Neurosurgery (B.M.), Sorbonne University, Paris, France; Departments of Neuroradiology (E.S., N.S., F.C.) and Neurosurgery (B.M.), Pitié-Salpêtrière University Hospital, Public Assistance-Paris Hospitals, Paris, France; Department of Pediatric Neurosurgery (T.B., S.S.), French Center for Pediatric Stroke, Department of Pediatric Imaging (Q.A., N.B., F.B., O.N., G.B.), Department of Pediatric Neurology (M.K.), French Center for Pediatric Stroke, and Department of Anesthesiology (P.M.), Necker-Enfants Malades University Hospital, Public Assistance-Paris Hospitals, Paris, France; Université de Paris (T.B., N.B., F.B., O.N., G.B.), Paris, France; Brain and Spine Institute (B.M.), Institut National de la Santé et de la Recherche Médicale, Unité Mixte de Recherche 1127; Centre National de la Recherche Scientifique, Unité Mixte de Recherche 7225, Paris, France; and Department of Neuroimaging (F.G.), Pellegrin Hospital, University Hospital of Bordeaux, Bordeaux, France.;

Paper previously presented at: French Days of Radiology, October 11-14, 2019; Paris, France.

Please address correspondence to Gregoire Boulouis, MD, Pediatric Radiology, Necker Enfants Malades, 149 rue de Sèvres, 75006 Paris, France; e-mail: gregoireboulouis@gmail.com; @gboulouis

http://dx.doi.org/10.3174/ajnr.A6824 considerable morbidity and mortality. The management of patients with unruptured brain AVMs relies on the evaluation of the riskbenefit balance between invasive treatment and follow-up. The optimal approach is yet to be determined in pediatric patients, ${ }^{2}$ in whom decisions are made more complex by the potential long life span and cumulative risk of rupture. Previous data have shown that brain AVM angioarchitecture evolves across time. ${ }^{3,4}$ On the basis of the common model of "wear and tear," brain AVMs are believed to rupture in sectors with more severe arterial and venous vasculopathies and increased frailty features, more frequently seen in adults than during childhood. Nonetheless, intracranial hemorrhage remains the most common revelation in children, and brain AVMs represent the leading etiology of intracranial hemorrhage in the pediatric group; thus, the identification of individual biomarkers associated with impending or higher risk of rupture is of crucial importance to guide therapeutic management. Several angioarchitectural brain AVM characteristics (deep location, exclusive deep venous drainage, associated aneurysms, or venous ectasia) $)^{5-7}$ have 
been identified as being more prevalent in ruptured than in unruptured brain AVMs, but these data are derived mostly from adult samples and remain scarce in pediatric populations. ${ }^{1,8}$ Furthermore, such findings do not formally allow identifying characteristics associated with earlier rupture, due to the great risk of recognition biases (eg, the higher prevalence of a biomarker in the ruptured population does not indicate that this biomarker is responsible for a rupture earlier in life).

In this retrospective multicentric cohort of children and adult patients with first brain AVM rupture, we aimed to determine brain AVM angioarchitectural characteristics associated with rupture early in life.

\section{MATERIALS AND METHODS Pediatric Cohort}

Pediatric patients with nontraumatic intracranial hemorrhage referred to a pediatric quaternary care center (Necker-Enfants Malades University Hospital), the coordinating center for the French Pediatric Stroke Network, are prospectively collected into an inception retrospective (2003-2008) and prospective (2008ongoing) registry, described in detail elsewhere. ${ }^{9,10}$ This registry was retrospectively queried to identify children with first ruptured brain AVMs. Patients meeting the following criteria were retrospectively screened for inclusion: 1) 28 days to 18 years of age at the time of symptom onset; 2) having nontraumatic intracerebral, intraparenchymal, or intraventricular hemorrhage; and 3) having a ruptured brain AVM.

\section{Adult Cohort}

Records of adult patients with brain AVMs referred to a distinct tertiary care center (Pitié-Salpêtrière University Hospital) between January 1, 2003, and February 1, 2018, as described in detail elsewhere, ${ }^{11}$ were retrospectively reviewed. Adult patients with ruptured brain AVMs, naive to any previous targeted treatment, were retrospectively screened for inclusion.

\section{Data Acquisition}

Clinical, demographic, and imaging data (brain 1.5T MR imaging, brain $\mathrm{CT}$, cerebral conventional angiography) were retrospectively assessed. Data included age at presentation, sex, admission Glasgow Coma Scale score, hemorrhage location and volume $(\mathrm{AxBxC} / 2$ method $^{12}$ ), as well as brain AVM angioarchitectural features (nidus size; maximal 2D diameter; location; Spetzler-Martin grade; ${ }^{13}$ venous drainage pattern as deep, superficial, or mixed; and nidal or arterial aneurysm). Per guidelines, we assessed the presence of deep venous drainage if the internal cerebral veins, basal veins, or precentral cerebral vein participated in the nidus venous drainage. ${ }^{14}$ All data were acquired in consensus by a distinct pair of interventional neuroradiologists ( 1 senior and 1 junior) in each cohort.

\section{Ethics}

All aspects of the study were in accordance with the General Data Protection Regulation and actual French law and ethics in healthrelated research. Institutional review board approval was obtained under the reference of Comité de Protection des Personnes Ile de France 3, 18062012. As in all observational studies with retrospective analysis of routinely acquired data, written informed consent was waived, and patients or children's parents could oppose the use of their health-related data. The article was prepared in accordance with the Strengthening the Reporting of Observational Studies in Epidemiology statement. ${ }^{15}$

\section{Statistics}

Continuous variables were expressed as mean \pm SD or median (interquartile range) as appropriate. Categoric variables were expressed as absolute numbers with percentages. We compared variable differences between the adult and pediatric cohort (using 18 years of age as a cutoff) univariable analyses with the $t$ test, Mann-Whitney $U$ test, $\chi^{2}$ test, and multivariate analysis of variance as appropriate. Variables associated with the pediatric cohort in univariable analyses at $P<.1$ were entered into a multivariable nominal logistic regression model; then, a backward elimination was used to eliminate nonsignificant variables. Considering age at presentation as a continuous variable, used as the time to rupture, we performed survival analyses. Data were not censored because birth was the chosen initiation of time to the event and intracranial hemorrhage presentation was the event. We first ran Kaplan-Meier analyses with significance testing with the log-rank test to determine univariate predictors of early rupture. Then we conducted univariable Cox proportional hazards analysis to calculate the unadjusted hazard ration (HR) for the risk of rupture. Variables with $P<.1$ in univariable Cox analysis were included in multivariable Cox proportional hazards models to determine adjusted HRs of early rupture. Twosided $P$ values $<.05$ were considered statistically significant. All statistical analyses were performed using JMP Pro 14.0 (SAS Institute).

\section{RESULTS}

\section{Patient Population and Baseline Characteristics}

A total of 122 children (mean, $9.8 \pm 3.8$ years of age) and 198 adult patients (mean, $43.3 \pm 15.7$ years of age) were included in the analysis. There was no difference regarding the female proportion (45.9\% versus $42.9 \%, P=.62$ ) or baseline Glasgow Coma Scale score between children and adults, respectively $(11.6 \pm 3.9$ versus $12.4 \pm 3.7, P=.09$ ) (Table 1). Age distribution at rupture is presented in Fig 1.

Hemorrhages were most commonly supratentorial, with no difference among cohorts $(76.7 \%$ versus $72.7 \%, P=.45)$. Intracranial hemorrhage volumes were significantly larger in adults than in children $(19.8 \pm 16.7$ versus $38.6 \pm 35.5 \mathrm{~mL}, P<.001)$.

\section{AVM Characteristics}

Pediatric-to-Adult Comparisons. In univariate analyses, brain AVMs in the pediatric group were more frequently deeply located (56.3\% versus $21.2 \%, P<.001)$ and larger $(24.2 \pm 14.3$ versus $18.9 \pm 14.3 \mathrm{~mm}, P=.002)$ with less frequent nidal $(15.9 \%$ versus $23.5 \%, P=.03)$ and prenidal arterial aneurysms (2.7\% versus $17.9 \%, P<.001)$. There was no significant difference in venous drainage patterns, Spetzler-Martin grade, and nidus location.

After we adjusted for sex, nidus size, pre- or nidal arterial aneurysm presence, and supratentorial location, the nidus size (adjusted OR, 0.95 per millimeter increase; 95\% CI, 0.93-0.97; $P<.001$ ), prenidal aneurysms (adjusted OR, 28.9; 95\% CI, 5.6$148 ; P<.001$ ), and nidal aneurysms (adjusted OR, 2.6; 95\% CI, $1.1-5.3 ; P=.006)$ showed a significant association with rupture AJNR Am J Neuroradiol 41:2358-63 Dec 2020 www.ajnr.org 
Table 1: Baseline clinical and imaging characteristics ${ }^{a}$

\begin{tabular}{lcccc}
\hline \multicolumn{1}{c}{ Variable } & Pediatric $(\boldsymbol{n}=122)$ & Adult $(\boldsymbol{n}=198)$ & All $(\boldsymbol{n}=320)$ & $\boldsymbol{P}$ Value \\
\hline Clinical presentation & & & & \\
Age (yr) & $9.8 \pm 3.8$ & $43.3 \pm 15.7$ & $30.8 \pm 20.6$ & $<.001$ \\
Female sex & $56(45.9 \%)$ & $85(42.9 \%)$ & $141(44.1 \%)$ & .62 \\
GCS at baseline & $11.6 \pm 3.9$ & $12.4 \pm 3.7$ & $12.1 \pm 3.8$ & .09 \\
GCS score $<9$ & $33(28 \%)$ & $38(21.2 \%)$ & $71(23.9 \%)$ & .09 \\
Imaging presentation & & & & .45 \\
Hemorrhage location & & & & \\
$\quad$ Supratentorial & $92(76.7 \%)$ & $128(72.7 \%)$ & $220(74.3 \%)$ & \\
Infratentorial & $16(13.3 \%)$ & $33(18.8 \%)$ & $49(16.6 \%)$ & \\
Other (SAH/IVH) & $12(10 \%)$ & $15(8.5 \%)$ & $27(9.1 \%)$ & \\
Hemorrhage volume $(\mathrm{mL})$ b & $19.8 \pm 16.7$ & $38.6 \pm 35.5$ & $30.6 \pm 30.4$ & $<.001$ \\
AVM characteristics & & & & \\
Deep location & $67(56.3 \%)$ & $42(21.2 \%)$ & $109(34.4 \%)$ & $<.001$ \\
Supratentorial location & $103(86.6 \%)$ & $153(77.3 \%)$ & $256(80.8 \%)$ & .052 \\
Nidus max. diameter & $24.2 \pm 14.3$ & $18.9 \pm 14.3$ & $20.9 \pm 14.5$ & .002 \\
Spetzler-Martin grade & & & & .7 \\
I & $24(20.9 \%)$ & $49(26.6 \%)$ & $73(24.4 \%)$ & \\
II & $50(43.5 \%)$ & $75(40.8 \%)$ & $125(41.8 \%)$ & \\
III & $27(23.5 \%)$ & $44(23.9 \%)$ & $71(23.7 \%)$ & \\
IV & $10(8.7 \%)$ & $11(6 \%)$ & $21(7 \%)$ & \\
V & $4(3.5 \%)$ & $5(2.7 \%)$ & $9(3 \%)$ & \\
AVM-related aneurysms & $18(15.9 \%)$ & $42(23.5 \%)$ & $60(20.5 \%)$ & .03 \\
Nidal aneurysm & $3(2.7 \%)$ & $32(17.9 \%)$ & $35(12 \%)$ & $<.001$ \\
Prenidal arterial aneurysm & $35(29.7 \%)$ & $46(25.8 \%)$ & $81(27.4 \%)$ & .87 \\
AVM venous drainage & $58(49.2 \%)$ & $86(48 \%)$ & $144(48.5 \%)$ & .85 \\
Exclusively deep & & & & \\
Any deep drainage & & & & \\
\hline
\end{tabular}

Note:-IVH indicates intraventricular hemorrhage; GCS, Glasgow Coma Scale; max., maximum.

${ }^{a}$ Data are presented as absolute count (percentage) and mean \pm SD as appropriate.

${ }^{b}$ For 114 and 155 patients with intraparenchymal hemorrhages.

60

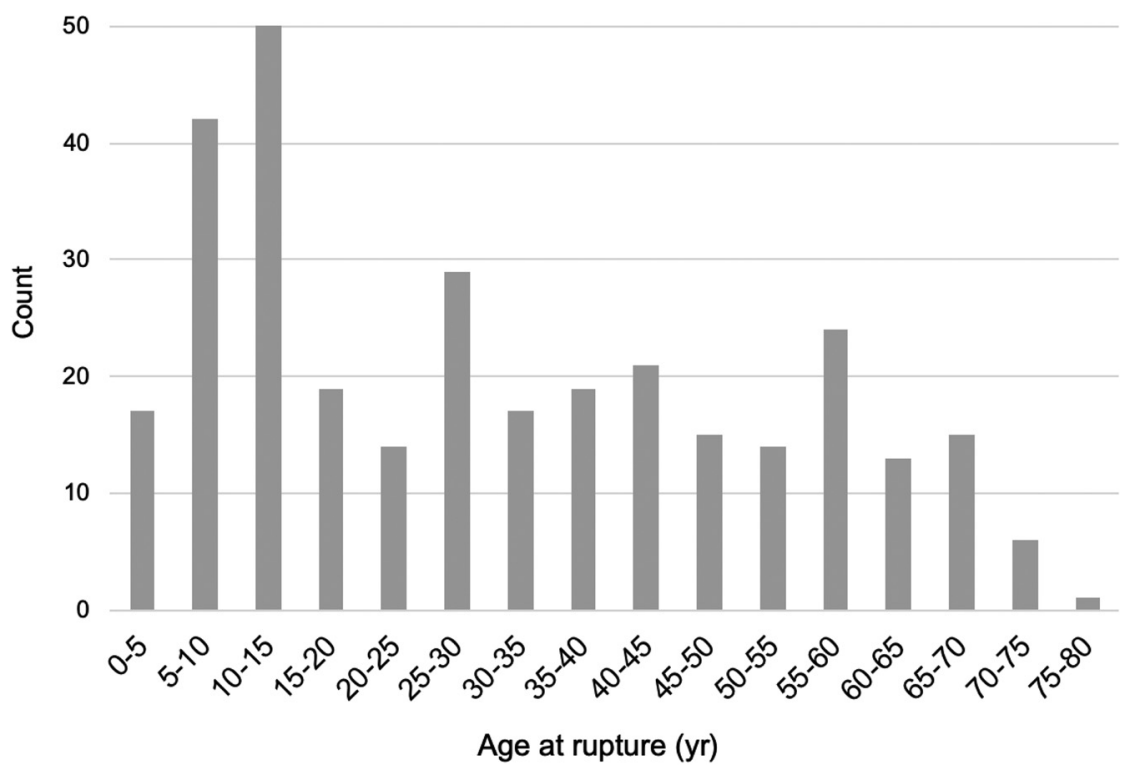

FIG 1. Age distribution at rupture in the study sample.

during adulthood. When we forced adjustment for the venous drainage pattern in the same model, deep venous drainage appeared as a risk factor for rupture during childhood (adjusted OR, 0.55 ; 95\% CI, 0.30-0.99; $P=.04$ ).
Birth-to-Rupture Survival Analyses. In univariate survival analysis, AVM supratentorial location, deep location, and exclusively deep venous drainage were associated with earlier rupture (log-rank, $P<.05$ for all), whereas nidal or prenidal arterial aneurysms were associated with later rupture (log-rank, $P<.001$ ) (Fig 2). There was no rupture-free survival difference based on the presence of any deep venous drainage (log-rank, $P=.61$ ).

Similar predictors were found in univariable Cox regression, and the fully adjusted proportional model found AVM supratentorial and deep locations (HR, 1.19; 95\% CI, 1.01$1.41 ; P=.03$ and HR, $1.43 ; 95 \% \mathrm{CI}$, $1.22-1.67 ; P<.001$, respectively) and the absence of an aneurysm (HR, 0.62 ; 95\% CI, $0.46-0.83 ; P<.001$ ) to be associated with earlier rupture (Table 2).

In the above-mentioned model, when we removed deep location to avoid confounding on the venous pattern, an exclusive deep venous drainage became a strong predictor of earlier rupture (adjusted relative risk, 1.46; 95\% CI, 1.21-1.76; $P<.001)$.

\section{DISCUSSION}

We found that supratentorial and deep locations and exclusive deep venous drainage were more frequently seen in pediatric than in adult ruptured brain AVMs and that these features were associated more generally with rupture earlier in life. We also found that nidal or afferent arterial aneurysms were more prevalent in brain AVMs that rupture later in the life span.

These results contribute to the evidence that various morphologic brain AVM characteristics are associated with brain AVM rupture at initial diagnosis. By inference, variables such as AVM size, deep venous drainage pattern, and associated arterial aneurysms have been considered "risk factors" for brain AVM hemorrhage in general. ${ }^{4,5,16-18}$ Here, we extend knowledge by characterizing patterns associated with rupture across the life span, that is, factors that influence or are seen at earlier or later rupture.

Age group is long known to strongly influence the presentation of brain $\mathrm{AVMs},{ }^{2}$ and it has been shown that brain AVMs in 


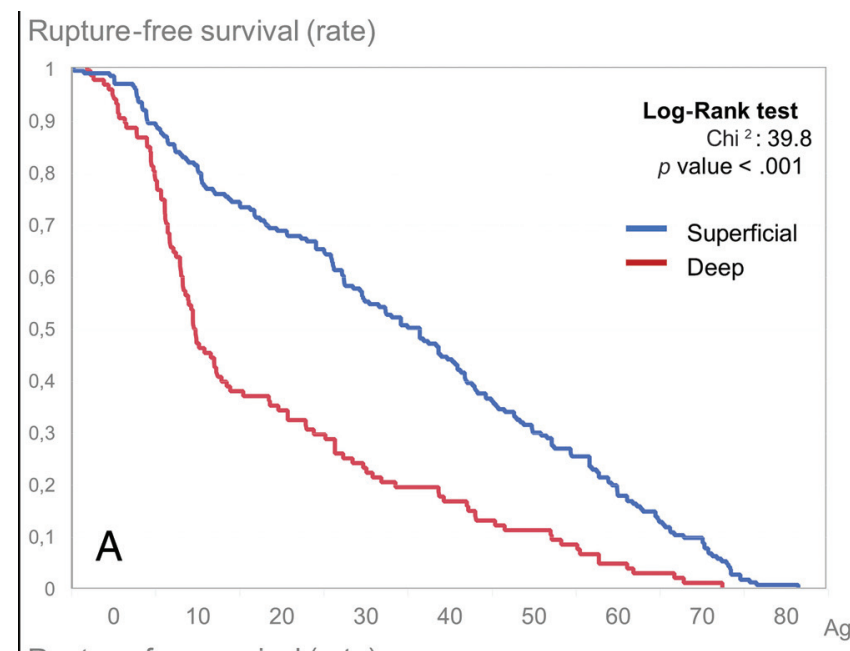

Rupture-free survival (rate)

Rupture-free survival (rate)
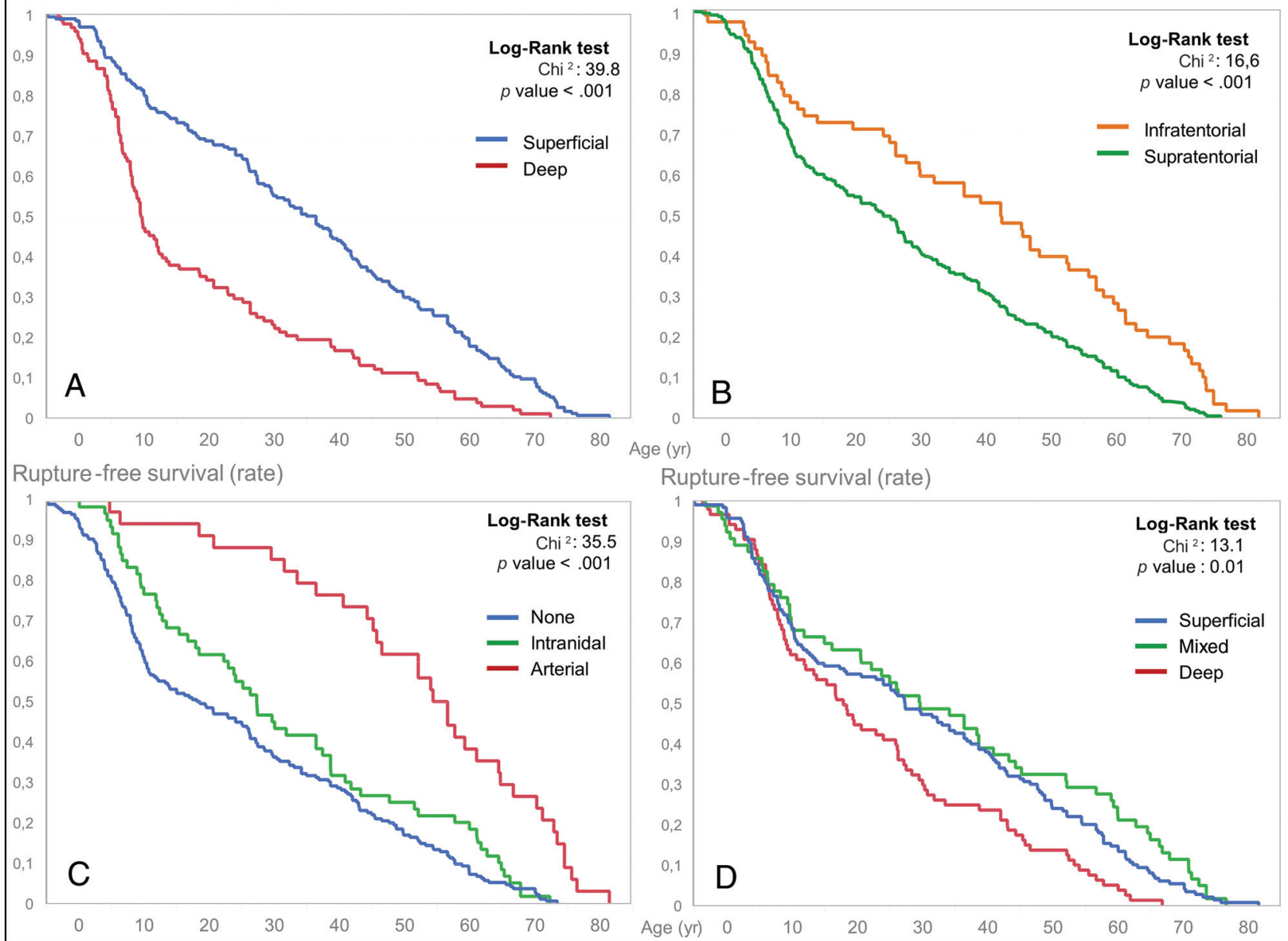

Rupture-free survival (rate)

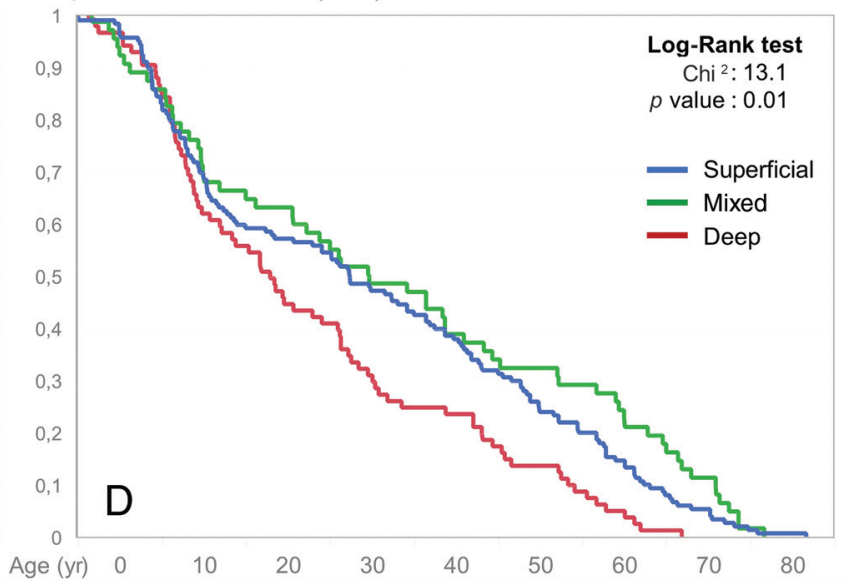

FIG 2. Rupture-free survival according to brain AVM characteristics, Kaplan-Meier survival curves, delay until rupture (age in years), and brain AVM location ( $A$ and $B)$, aneurysm presence $(C)$, and venous drainage pattern $(D)$.

Table 2: Uni- and multivariable proportional hazards for time to rupture

\begin{tabular}{|c|c|c|c|c|c|c|}
\hline \multirow[b]{2}{*}{ Variable } & \multicolumn{3}{|c|}{ Univariable $^{a}$} & \multicolumn{3}{|c|}{ Multivariable $^{\mathrm{b}}$} \\
\hline & RR & $95 \% \mathrm{Cl}$ & $P$ Value & aRR & $95 \% \mathrm{Cl}$ & $P$ Value \\
\hline Brain AVM supratentorial location & 1.46 & $1.21-1.76$ & $<.001$ & 1.19 & $1.01-1.41$ & .03 \\
\hline Brain AVM deep location & 1.46 & $1.29-1.65$ & $<.001$ & 1.43 & $1.22-1.67$ & $<.001$ \\
\hline Nidus size & 1 & $1-1.01$ & .36 & & & \\
\hline Prenidal arterial aneurysm & 0.5 & $0.37-0.65$ & $<.001$ & 0.62 & $0.46-0.83$ & $<.001$ \\
\hline Intranidal aneurysm & 1.25 & $1-1.55$ & .27 & & & \\
\hline Any deep venous drainage & 1.03 & $0.92-1.16$ & .61 & & & \\
\hline Exclusively deep venous drainage & 1.39 & $1.16-1.67$ & .002 & 1.12 & $0.9-1.4$ & .43 \\
\hline
\end{tabular}

Note:-RR indicates relative risk; aRR, adjusted relative risk.

${ }^{\text {a }}$ Confidence intervals are profile-likelihood.

${ }^{\mathrm{b}}$ Confidence intervals are Wald.

children disproportionately present with intracranial hemorrhage compared with adults. This finding has led to the common belief that children are at higher risk for brain AVM rupture. Yet, the higher rates of hemorrhages in children with brain AVMs is debated because they may result from confounding by presentation. In other words, the higher rate of hemorrhage in children may only result from children having fewer reasons to undergo brain imaging and have a fortuitous (or near-fortuitous, for instance in headaches) discovery of their brain AVM, in turn raising the proportion of brain AVMs discovered after a rupture. This has been shown to be true even after correcting for a potential informative censoring (ie, the higher rate of preventive treatment in nonhemorrhagic pediatric brain AVMs). ${ }^{2}$ Other authors, alternatively, believe that the difference in hemorrhagic rates may be the result of biologic differences leading to more aggressive/ frail brain AVMs that rupture early in children.

Among angioarchitectural characteristics of brain AVMs reported to be associated with rupture at presentation, ${ }^{1,6,8,18-21}$ 
smaller nidus size was long considered a major rupture risk factor in brain AVM natural history. ${ }^{22-24}$ This could be interpreted as a contradiction to our finding because early rupture was associated with larger nidus size. However, in the absence of a control group comprising patients with unruptured brain AVMs, we cannot conclude about the absolute or relative risk of rupture but only infer from survival models that among patients who will experience a rupture, larger brain AVMs are likely to rupture earlier. Furthermore, larger nidi are more likely to become symptomatic in the absence of bleeding than smaller ones, with a higher risk for causing epilepsy or headaches, conditions for which children may be less likely to get brain imaging than adults; this feature may, in turn, explain the over-representation of smaller brain AVMs in previously reported samples of ruptured (versus unruptured) lesions. Furthermore, larger AVMs may uniquely express a hemodynamic or biologic feature that promotes early rupture, but the particular feature may be expressed at a low frequency, yielding to the alternate hypothesis that the risk of rupture may be generally lower for large AVMs, but when larger AVMs rupture, it happens earlier in life.

Recognition bias from previously published works may also explain our finding that supratentorial (rather than infratentorial) location was associated with earlier rupture, challenging the results of Ellis et $\mathrm{al}^{6}$ and Oulasvirta et al, ${ }^{8}$ who observed the opposite. These seemingly contradictory results likely reflect infratentorial brain AVMs only coming to clinical attention after a rupture, while supratentorial lesions may present with other symptoms. Our results, in that sense, add key additional data by establishing that among brain AVMs that first present with hemorrhage, both supratentorial location and larger AVMs are associated with earlier rupture.

We found arterial and intranidal aneurysms to be associated with rupture later in life. In previous studies, Hetts et $\mathrm{al}^{1}$ and Stapf et $\mathrm{al}^{25}$ found that aneurysms were significantly associated with later AVM diagnosis, and several converging reports indicate that arterial and nidal aneurysms are more common in older individuals and disproportionately more so in late hemorrhagic presentations. ${ }^{1,2,6,26}$ These data as well as our results indicate that these frailty features develop later in life, possibly due to chronic hemodynamic stress, ${ }^{27}$ mandate life-long follow-up to detect their appearance, and potentially indicate impending or higher risk of bleeding. ${ }^{18}$ Our results in that sense reinforce the assertion that aneurysms (whether arterial or nidal) are manifestations of wear and tear of AVMs forming through a cumulative damage processes and are, therefore, expected to be acquired across time and be expressed more frequently in older patients with AVMs.

The main limitations include the retrospective nature of our study and our results being derived from 2 distinct populations, when it is known that brain AVM characteristics may be heterogeneous across settings. ${ }^{28}$ We believe this feature to be a very unlikely source of confusion, given the geographic proximity of both including centers ( 3 kilometers) and the potential population pool differing only in age.

\section{CONCLUSIONS}

In this large sample of pediatric and adult patients with ruptured brain AVMs, we demonstrated significantly different architectural features according to age at rupture and showed that earlier rupture was associated with deep, supratentorial brain AVMs with exclusively deep venous drainage, whereas aneurysms (nidal or arterial) were associated with later rupture. Whether these differences reflect biases versus biologic differences in the natural history of brain AVMs along the life span deserves further study.

Disclosures: Nader Sourour-UNRELATED: Consultancy: Medtronic, Balt, MicroVention. Frederic Clarençon-UNRELATED: Board Membership: ArteDrone; Payment for Lectures Including Service on Speakers Bureaus: Penumbra, Stryker, Balt, MicroVention.

\section{REFERENCES}

1. Hetts SW, Cooke DL, Nelson J, et al. Influence of patient age on angioarchitecture of brain arteriovenous malformations. AJNR Am J Neuroradiol 2014;35:1376-80 CrossRef Medline

2. Fullerton HJ, Achrol AS, Johnston SC, et al; UCSF BAVM Study Project. Long-term hemorrhage risk in children versus adults with brain arteriovenous malformations. Stroke 2005;36:2099-2104 CrossRef

3. Sure U, Butz N, Schlegel J, et al. Endothelial proliferation, neoangiogenesis, and potential de novo generation of cerebrovascular malformations. J Neurosurg 2001;94:972-77 CrossRef Medline

4. Redekop G, TerBrugge K, Montanera W, et al. Arterial aneurysms associated with cerebral arteriovenous malformations: classification, incidence, and risk of hemorrhage. J Neurosurg 1998;89:539-46 CrossRef

5. Gross BA, Du R. Natural history of cerebral arteriovenous malformations: a meta-analysis. J Neurosurg 2013;118:437-43 CrossRef Medline

6. Ellis MJ, Armstrong D, Vachhrajani S, et al. Angioarchitectural features associated with hemorrhagic presentation in pediatric cerebral arteriovenous malformations. J Neurointerv Surg 2013;5:19195 CrossRef Medline

7. Kim H, Al-Shahi Salman R, McCulloch CE, et al; MARS Coinvestigators. Untreated brain arteriovenous malformation: patient-level meta-analysis of hemorrhage predictors. Neurology 2014;83:590-97 CrossRef Medline

8. Oulasvirta E, Koroknay-Pal P, Hafez A, et al. Characteristics and long-term outcome of 127 children with cerebral arteriovenous malformations. Neurosurgery 2019;84:151-59 CrossRef Medline

9. Guédon A, Blauwblomme T, Boulouis G, et al. Predictors of outcome in patients with pediatric intracerebral hemorrhage: development and validation of a modified score. Radiology 2018;286:651-58 CrossRef

10. Blauwblomme T, Bourgeois M, Meyer P, et al. Long-term outcome of 106 consecutive pediatric ruptured brain arteriovenous malformations after combined treatment. Stroke 2014;45:1664-71 CrossRef

11. Shotar E, Amouyal C, Jacquens A, et al. S100B serum elevation predicts in-hospital mortality after brain arteriovenous malformation rupture. Stroke 2019;50:1250-53 CrossRef Medline

12. Kothari RU, Brott T, Broderick JP, et al. The ABCs of measuring intracerebral hemorrhage volumes. Stroke 1996;27:1304-05 CrossRef Medline

13. Spetzler RF, Martin NA. A proposed grading system for arteriovenous malformations. J Neurosurg 1986;65:476-83 CrossRef Medline

14. Atkinson RP, Awad IA, Batjer HH, et al; Joint Writing Group of the Technology Assessment Committee American Society of Interventional and Therapeutic Neuroradiology; Joint Section on Cerebrovascular Neurosurgery a Section of the American Association of Neurological Surgeons and Congress of Neurological Surgeons; Section of Stroke and the Section of Interventional Neurology of the American Academy of Neurology. Reporting terminology for brain arteriovenous malformation clinical and radiographic features for use in clinical trials. Stroke 2001;32:1430-42 CrossRef Medline

15. von Elm E, Altman DG, Egger $M$, et al; STROBE Initiative. The Strengthening the Reporting of Observational Studies in Epidemiology (STROBE) Statement: guidelines for reporting observational studies. Int J Surg 2014;12:1495-99 CrossRef Medline 
16. Shotar E, Pistocchi S, Haffaf I, et al. Early rebleeding after brain arteriovenous malformation rupture, clinical impact and predictive factors: a monocentric retrospective cohort study. Cerebrovasc Dis 2017;44:304-12 CrossRef Medline

17. Nataf F, Meder JF, Roux FX, et al. Angioarchitecture associated with haemorrhage in cerebral arteriovenous malformations: a prognostic statistical model. Neuroradiology 1997;39:52-58 CrossRef Medline

18. Stapf C, Mast H, Sciacca RR, et al. Predictors of hemorrhage in patients with untreated brain arteriovenous malformation. Neurology 2006;66:1350-55 CrossRef Medline

19. Yamada S, Takagi Y, Nozaki K, et al. Risk factors for subsequent hemorrhage in patients with cerebral arteriovenous malformations. J Neurosurg 2007;107:965-72 CrossRef Medline

20. Langer DJ, Lasner TM, Hurst RW, et al. Hypertension, small size, and deep venous drainage are associated with risk of hemorrhagic presentation of cerebral arteriovenous malformations. Neurosurgery 1998;42:481-86; discussion 487-89 Medline

21. Spetzler RF, Hargraves RW, McCormick PW, et al. Relationship of perfusion pressure and size to risk of hemorrhage from arteriovenous malformations. J Neurosurg 1992;76:918-23 CrossRef Medline

22. Ai X, Ye Z, Xu J, et al. The factors associated with hemorrhagic presentation in children with untreated brain arteriovenous malformation: a meta-analysis. J Neurosurg Pediatr 2019;23:343-54 CrossRef
23. Anderson RC, McDowell MM, Kellner CP, et al. Arteriovenous malformation-associated aneurysms in the pediatric population. $J$ Neurosurg Pediatr 2012;9:11-16 CrossRef Medline

24. Hoffman C, Riina HA, Stieg P, et al. Associated aneurysms in pediatric arteriovenous malformations and the implications for treatment. Neurosurgery 2011;69:315-22 CrossRef Medline

25. Stapf C, Khaw AV, Sciacca RR, et al. Effect of age on clinical and morphological characteristics in patients with brain arteriovenous malformation. Stroke 2003;34:2664-69 CrossRef Medline

26. Turjman F, Massoud TF, Vinuela F, et al. Correlation of the angioarchitectural features of cerebral arteriovenous malformations with clinical presentation of hemorrhage. Neurosurgery 1995;37:856-60; discussion 860-62 CrossRef Medline

27. Shakur SF, Amin-Hanjani S, Mostafa H, et al. Hemodynamic characteristics of cerebral arteriovenous malformation feeder vessels with and without aneurysms. Stroke 2015;46:1997-99 CrossRef Medline

28. Halim AX, Singh V, Johnston SC, et al; UCSF BAVM Study Project: Brain Arteriovenous Malformation. Characteristics of brain arteriovenous malformations with coexisting aneurysms: a comparison of two referral centers. Stroke 2002;33:675-79 CrossRef Medline 